\title{
Risk of myocardial infarction in young female smokers
} N R Dunn, B Faragher, M Thorogood, L de Caestecker, T M MacDonald, C McCollum,
S Thomas, R Mann
Drug Safety Research Unit, Bursledon Hall, Southampton

SO31 1AA, UK

N R Dunn

R Mann

Department of

Organisational Health

Psychology,

Manchester School of

Management, UMIST,

PO Box 88,

Manchester M60 1QD,

UK

B Faragher

London School of

Hygiene and Tropical

Medicine, Keppel

Street, London

WC1 6FH, UK

M Thorogood

Department of Public Health, Greater

Glasgow Health Board, Dalian House, 350 St

Vincent Street,

Glasgow G3 8YU, UK

$\mathrm{L}$ de Caestecker

Medicines Monitoring Unit, Department of Clinical Pharmacology and Therapeutics,

Ninewells Hospital

Medical School,

Dundee DD1 9SY, UK

T M MacDonald

Department of

Surgery, South

Manchester University

Hospital, Nell Lane,

West Didsbury,

Manchester M20 8LR,

UK

C McCollum

Wolfson Unit of

Clinical

Pharmacology,

University of

Newcastle, Newcastle upon Tyne NE2 4HH, UK

S Thomas

Correspondence to: Dr Dunn.

email: ndunn@dsru.

u-net.com

Accepted for publication 4 June 1999
Abstract

Objectives-To determine the extent of risk of myocardial infarction from cigarette smoking in young women, and to examine the relation of smoking with other putative risk factors.

Design-Community based case control study.

Setting-England, Scotland, and Wales.

Patients-Women $(n=448)$ between 16 and 44 years old with a diagnosis of incident myocardial infarction between 1 October 1993 and 16 October 1995. Controls $(n=1728)$ were age and general practice matched women without a diagnosis of myocardial infarction.

Outcomes measures-Odds ratios for risk of myocardial infarction associated with smoking and other risk factors.

Results-Odds ratios for myocardial infarction in smokers versus non-smokers showed a strong dose response, from 2.47 (95\% confidence interval (CI) 1.12 to 5.45 ) in smokers of $1-5$ cigarettes per day to 74.6 $(95 \%$ CI 33.0 to 169$)$ in smokers of $\geqslant 40$ cigarettes per day. There was no interaction of smoking with use of oral contraceptives, but there were additive risks with other clinical risk factors such as hypertension and diabetes. It is estimated that if all women aged 16-44 years were able to stop smoking, 400 cases of myocardial infarction per annum (of whom 112 would die) would be prevented.

Conclusions-In young women the risk of myocardial infarction from smoking was considerable, and heavy smokers with other risk factors were especially at risk.

(Heart 1999;82:581-583)

Keywords: myocardial infarction; smoking; risk factors

Coronary heart disease is the leading cause of death in men in the UK, and is also very important in women as a cause of death and disability. ${ }^{1}$ Most coronary heart disease is found in the older age groups, but it also occurs in younger people, with a lower prevalence in women than men. The majority of epidemiological studies on coronary heart disease have concentrated on middle aged or older men, but it is possible that the importance of risk factors may vary between the sexes, especially among the young, in whom there are metabolic differences related to hormonal factors. Some studies have suggested that there is an interaction between the use of oral contraceptives and smoking. ${ }^{23}$ In this paper, we present detailed data on smoking as a risk factor, and examine the relation between smoking and other potential risk factors in determining the overall risk for myocardial infarction in younger women.

\section{Methods}

The data were taken from the MICA (myocardial infarction causality) study, which was a community based case control study within England, Scotland, and Wales that examined the association between myocardial infarction and use of oral contraception. ${ }^{4}$ Its main results have been published elsewhere. ${ }^{5}$ Cases were women aged 16-44 years, who had a myocardial infarction between 1 October 1993 and 16 October 1995. Potential cases were identified from hospital inpatient statistics, or death certificates, using the World Health Organisation's International Classification of Diseases diagnostic codes 410 (version 9) or I21 (version 10). Each case diagnosis was validated by three cardiologists, blinded to exposure status, based on WHO criteria. ${ }^{6}$ Controls were age, and general practice, matched women with no myocardial infarction. There were exclusion criteria for cases and controls based on factors that would make it unlikely that the woman would be taking an oral contraceptive-for example, past history of hysterectomy, cancer of the ovary or breast, or pregnancy at the time of the myocardial infarction. Data on exposure and risk factors were obtained by interview with the subject (or her proxy, when deceased), conducted by trained research nurses. These nurses were subjected to quality assessment by tape recording and accompanied interviews, and selected data were validated by checking against the subject's general practitioner (or family planning) records, although we have only used interview data in the analysis in this paper.

Statistical analysis was carried out on Stata 5 (Statacorp, Texas, USA), using unconditional logistic regression to compute odds ratios within the whole dataset, and unconditional logistic regression where subgroups were created.

\section{Results}

We identified 1224 potential cases from source data, of whom $882(72 \%)$ were alive. There were 448 validated and interviewed cases of myocardial infarction, and 1728 controls included in the analysis. Table 1 shows the distribution of important variables between cases and controls. All the variables were associated with an increased risk of myocardial infarction, with the exception of use of oral contraceptives. 
Table 1 Distribution and univariate odds ratios of selected variables between cases and controls

\begin{tabular}{|c|c|c|c|}
\hline \multirow[b]{2}{*}{ Variable } & \multicolumn{2}{|c|}{$\begin{array}{l}\text { Positive recording ( } n(\%) \text { except } \\
\text { where indicated) }\end{array}$} & \multirow{2}{*}{$\begin{array}{l}\text { Univariate odds ratio } \\
(95 \% \mathrm{CI})\end{array}$} \\
\hline & Cases & Controls & \\
\hline $\begin{array}{l}\text { Age (years) (median) } \\
\text { (interquartile range) }\end{array}$ & $\begin{array}{l}40.6 \\
(37.4-42.9)\end{array}$ & $\begin{array}{l}40.7 \\
(37.4-42.9)\end{array}$ & \\
\hline \multicolumn{4}{|l|}{ Past medical history } \\
\hline Hypertension & $81(18.1)$ & $88(5.1)$ & $4.23(3.03$ to 5.89$)$ \\
\hline Angina & $22(4.9)$ & $10(0.6)$ & 9.27 (4.26 to 20.2$)$ \\
\hline Hyperlipidaemia & $34(7.6)$ & $51(3.0)$ & $2.68(1.70$ to 4.23$)$ \\
\hline Diabetes mellitus & $52(11.6)$ & $17(1.0)$ & $14.1(7.82$ to 25.5$)$ \\
\hline \multicolumn{4}{|l|}{ Smoking history } \\
\hline Smoked in last year & $360(80.4)$ & $520(30.1)$ & 9.99 (7.58 to 13.2$)$ \\
\hline Ever smoked cigarettes & $394(87.9)$ & $899(52.0)$ & $6.88(5.05$ to 9.36$)$ \\
\hline \multicolumn{4}{|l|}{ Contraception } \\
\hline Combined oral contraceptive ${ }^{\star}$ & $40(9.2)$ & $180(10.7)$ & $0.79(0.54$ to 1.17$)$ \\
\hline
\end{tabular}

${ }^{\star}$ Use within three months before myocardial infarction.

Table 2 Conditional odds ratios for myocardial infarction by different levels of reported cigarette consumption, and for smoking overall

\begin{tabular}{llll}
\hline $\begin{array}{l}\text { Cigarettes } \\
\text { per day }(n)\end{array}$ & $\begin{array}{l}\text { Cases } \\
n(\%)\end{array}$ & $\begin{array}{l}\text { Controls } \\
n(\%)\end{array}$ & $\begin{array}{l}\text { Odds ratio } \\
\text { (95\% CI })\end{array}$ \\
\hline 0 & $88(19.6)$ & $1208(70.0)$ & 1 \\
$1-5$ & $10(2.2)$ & $42(2.4)$ & $2.49(1.13$ to 5.52$)$ \\
$6-10$ & $32(7.1)$ & $113(6.5)$ & $4.07(2.54$ to 6.52$)$ \\
$11-19$ & $65(14.5)$ & $117(6.8)$ & $7.94(5.26$ to 11.99$)$ \\
$20-39$ & $209(46.7)$ & $238(13.8)$ & $14.03(10.12$ to 19.47$)$ \\
$\geqslant 40$ & $44(9.8)$ & $9(0.5)$ & $74.64(32.97$ to 168.9$)$ \\
All smokers & $360(80.4)$ & $519(30.1)$ & $9.99(7.59$ to 13.2$)$ \\
\hline
\end{tabular}

Table 3 Conditional odds ratios (95\% confidence intervals) for myocardial infarction by combinations of reported cigarette consumption and number of clinical risk factors present

\begin{tabular}{llll}
\hline & & \multicolumn{2}{l}{ Cigarettes per day } \\
\cline { 3 - 4 } $\begin{array}{l}\text { Clinical risk } \\
\text { factors }(n)^{*}\end{array}$ & Non-smokers & $1-19$ & $\geqslant 20$ \\
\hline 0 & 1 & $2.51(1.07$ to 5.91$)$ & $14.5(7.22$ to 29.3$)$ \\
1 & $1.22(0.62$ to 2.4$)$ & $9.11(4.66$ to 17.8$)$ & $26.1(14.0$ to 48.7$)$ \\
2 & $3.04(1.53$ to 6.06$)$ & $12.5(5.68$ to 27.4$)$ & $36.2(18.9$ to 69.5$)$ \\
33 & $6.74(3.46$ to 13.1$)$ & $35.8(17.9$ to 71.8$)$ & $66.8(34.7$ to 129$)$ \\
\hline
\end{tabular}

${ }^{\star}$ Hypertension, hyperlipidaemia, angina, or diabetes mellitus.

Table 4 Unconditional odds ratios for myocardial infarction in users of combined oral contraceptives, stratified by smoking habit, in those without clinical risk factors

\begin{tabular}{llll}
\hline & & \multicolumn{2}{l}{ Smokers } \\
\cline { 3 - 4 } Oral contraceptive & Non-smokers & 1-19 cigarettes/day & 20+ cigarettes/day \\
\hline Non-users & $44 / 931(4.5)$ & $57 / 217(20.8)$ & $151 / 192(44.0)$ \\
OR $(95 \%$ CI $)$ & 1 & 1 & 1 \\
Combined* & $6 / 131(4.4)$ & $11 / 23(32.4)$ & $15 / 19(44.1)$ \\
OR $(95 \% \mathrm{CI})$ & $0.97(0.41$ to 2.32$)$ & $1.82(0.84$ to 3.95$)$ & $1.0(0.49$ to 1.94$)$ \\
\hline
\end{tabular}

Values are number of cases/controls (\% cases/total).

${ }^{\star}$ Containing $\leqslant 35 \mu \mathrm{g}$ ethinyloestradiol and progestogen

Age was not considered as a risk factor because of the study design, in which we achieved very close age matching.

Table 2 shows the odds ratios for smoking stratified by the reported daily consumption of cigarettes. There was a significant increase in risk even at very low levels of smoking and a steady increase in risk with increasing cigarette consumption.

Table 3 shows the risk of myocardial infarction in women with combinations of clinical risk factors (angina, diabetes, hyperlipidaemia, or hypertension) and smoking. In each stratum of smoking, there was an additional risk with increasing risk factors. The interaction term between smoking and clinical risk factors was not significant. The effect of smoking was more pronounced than that of the clinical risk factors.
Table 4 shows the relation between smoking and use of combined oral contraceptives. Although the odds ratios for smokers of 1-19 cigarettes per day were higher than for smokers of $\geqslant 20$ cigarettes, the confidence intervals (CIs) were wide, and overlapped both the nonsmokers and the heavy smokers. There were no significant interactions, although the numbers of women on these pills were small, and thus the results were, to an extent, inconclusive.

\section{Discussion}

These data showed the extent of the risk of myocardial infarction associated with smoking in this age group of women. This increased considerably with increasing numbers of cigarettes smoked per day. Also, there was a further increase in risk when smoking was combined with other cardiovascular risk factors, although there was no evidence of interaction with use of the contraceptive pill.

Although myocardial infarction is comparatively rare in this group of women, we have estimated the age standardised incidence of myocardial infarction among women aged 16-44 years as 4.78 cases per 100000 woman years, with a maximum of 17.0 in the $40-44$ year age group (MICA study, unpublished data, 1998). The case fatality rate was $28 \%$ in the MICA study. ${ }^{5}$ We have also shown that the population attributable risk fraction for smoking in women aged 16-44 years was $73 \% .^{5}$ If all smokers among women aged 16-44 years were able to stop, this would potentially prevent 3.5 cases per 100000 women in a year, or 401 cases per annum (of which 112 cases would have been fatal), in England, Scotland, and Wales. Targeting advice on smoking to women with multiple risk factors would clearly have the greatest potential reward.

A potential weakness with this study is that we only interviewed $60 \%$ of the eligible cases ( $73 \%$ of live, $20 \%$ of proxy for deceased). This may have introduced a selection bias, if, for example, cases (or their proxy) who were heavy smokers were less likely to be interviewed. It is also possible that those controls who agreed to be interviewed were not typical of the general population, although table 2 shows that $30.1 \%$ of the controls were smokers, and this compares with national figures of $30 \%$ in the age group 35-49 years. ${ }^{7}$ Another possible weakness is that we used interview data to assess smoking. It is probable that women underestimated their consumption of cigarettes, and this might be different between cases and controls, which would lead to misclassification bias.

Detailed risk estimates for women of this age were not easy to find in the published literature. Most studies had data for women of all age groups, in whom the relative risks for smokers versus non-smokers varied from twofold to fourfold. Prescott and colleagues found a relative risk of 2.82 (95\% CI 1.45 to 5.46) for all women smokers, with the highest relative risk (6.8) found in women under age 55 years. ${ }^{8}$ They found no interaction between smoking and other risk factors. Three recent studies found adjusted odds ratios for myocardial infarction in young female smokers versus 
non-smokers compatible with the present study: 11.1 (95\% CI 5.68 to 21.8$),{ }^{2} 9.72$ (95\% CI 5.58 to 16.93$),{ }^{9}$ and 8.31 (95\% CI 4.74 to 14.57), ${ }^{10}$ respectively. The WHO study found an interaction between oral contraceptive use and smoking: odds ratio of 87.0 (95\% CI 29.8 to 254) for women with both variables. ${ }^{2}$ Rosenberg and colleagues used data from a large case control study in the US, and found relative risks for heavy smokers $(>35$ cigarettes per day) of 7.0 and 1.5 for light smokers $(<15$ cigarettes per day). ${ }^{3}$ The relative risks were considerably less than those found in the present study, but similar in magnitude to those reported by Mann and colleagues in young women. ${ }^{11}$ This US study also found evidence of an interaction between oral contraceptive use and smoking. This interaction was also reported in the data from the study by the Royal College of General Practitioners (RCGP). ${ }^{12}$ Comparisons between the present study and those of the RCGP ${ }^{12}$ and Rosenberg and colleagues ${ }^{3}$ are complicated by the fact that the predominant type of oral contraceptive used has changed over time, with oestrogen dose per pill falling and the introduction of products containing the progestogens desogestrel and gestodene, which had gained about $34 \%$ of the market in the UK by $1995 .{ }^{13}$ The more recent WHO study ${ }^{2}$ had few subjects taking oral contraceptives with desogestrel or gestodene (three cases and five controls, as compared to 20 cases and 61 controls in the present study), and 31 cases and 43 controls in Europe taking pills with $>50 \mu \mathrm{g}$ of oestrogen, as opposed to only one case and two controls in the present study. Thus it is possible that the absence of an interaction between smoking and oral contraceptive use in the present study, as compared to the others, reflects the changes in formulation of the pill. Also, smoking habits (such as inhalation) and cigarette strengths have probably changed in recent years.

Finally, in view of the suggestion that women might be more sensitive to the harmful effects of smoking compared to men, possibly because of a relative oestrogen deficiency in smokers, ${ }^{14}$ it is of interest to compare these results with odds ratios for smoking risk in men of a similar age group. However, comparable data on morbidity in the correct age group was not readily available, although Doll and Peto showed a relative risk of mortality from ischaemic heart disease of 14.8 in British male doctors aged $<45$ years who smoked $\geqslant 25$ cigarettes per day compared to non-smokers. ${ }^{15}$ This relative risk is comparable to the results in this paper. Morbidity data from the British regional heart study showed a relative risk of 3 (95\% CI 1.8 to 4.8 ) for major coronary events in male smokers of 20 cigarettes per day compared with non-smokers, ${ }^{16}$ but this cohort consisted of subjects aged $40-59$ years, and age has a strong influence on the relative risk.

\section{CONCLUSIONS}

The odds ratio of myocardial infarction associated with smoking cigarettes in young women was large, and increased progressively with consumption. Although myocardial infarction was rare in this age group of women, in the UK about 400 cases per year could be prevented and about 112 lives saved (assuming a case fatality rate of $28 \%$ ) if smoking ceased. Heavy smokers with other risk factors-for example, hypertension or diabetes mellitus-were particularly at risk of myocardial infarction.

We thank all the women and next of kin who agreed to be interviewed, and the staff in collaborating centres in Southampton, Manchester, Newcastle, and Glasgow who made vital contributions to the success of this study. The study was sponsored by tions to the success of this study.
NV Organon and Schering AG.

1 British Heart Foundation. Coronary heart disease statistics 1997. London: British Heart Foundation, 1997.

2 World Health Organization Collaborative Study of Cardiovascular Disease and Steroid Hormone Contraception. Acute myocardial infarction and combined oral contraceptives: results of an international case-control study. Lancet 1997;349:1202-9.

3 Rosenberg L, Kaufman DW, Helmrich SP, et al. Myocardial infarction and cigarette smoking in women younger than 50 years of age. FAMA 1985;253:2965-9.

4 Dunn NR, Thorogood M, de Caestecker L, et al. Myocardial infarction and oral contraceptives, a retrospective case-control study in England and Scotland (MICA study). Pharmacoepidemiology and Drug Safety 1997;6:2839.

5 Dunn NR, Thorogood M, Faragher B, et al. Oral contraceptives and myocardial infarction: results of the MICA casecontrol study. BMY. [In press.]

6 World Health Organization Collaborative Study of Cardiovascular Disease and Steroid Hormone Contraception. A multinational case-control study of cardiovascular disease and steroid hormone contraceptives. F Clin Epidemiol 1995; 48:1513-47.

7 Anon. Living in Britain 1996. London: HMSO, 1997.

8 Prescott E, Hippe M, Schnohr P, et al. Smoking and risk of myocardial infarction in women and men: longitudinal population study. BMF 1998;316:1043-7.

9 Lewis MA, Heinemann LAJ, Spitzer WO, et al on behalf of Trans-National Research Group on Oral Contraceptives and the Health of Young Women. The use of oral contraceptives and the occurrence of acute myocardial infarction in young women. Contraception 1997;56:129-40.

10 Sydney S, Pettiti DB, Quesenbery CP, et al. Myocardial infarction in users of low dose oral contraceptives. Obstet arction in users of low
Gynecol 1996;88:939-44.

11 Mann JI, Doll R, Thorogood M, et al. Risk factors for myocardial infarction in young women. Br f Prev Soc Med 1976;30:94-100.

12 Croft P, Hannaford PC. Risk factors for acute myocardial infarction in women: evidence from the Royal College of General Practitioners' oral contraceptive study. BMF 1989; 298:165-8.

13 Farley TMM, Meirik O, Lan Chang C, et al. Combined oral contraceptives, smoking and cardiovascular risk. If Epidemiol Community Health 1998;52:775-85.

14 Baron JA, Vecchia CL, Levi F. The antiestrogenic effect of cigarette smoke in women. Am $\mathcal{F}$ Obstet Gynecol 1990;162: 502-14.

15 Doll R, Peto R. Mortality in relation to smoking: 20 years' observation on male British doctors. BMF 1976;ii:152536.

16 Cook DG, Shaper AG, Pocock SJ, et al. Giving up smoking and the risk of heart attacks: a report from the British regional heart study. Lancet 1986;ii:1376-80. 